\title{
Correction to: Acute Knee Dislocations
}

Conor I. Murphy, Philip P. Roessler,

Tracye J. Lawyer, and Volker Musahl

\section{Correction to:}

Chapter 11 in: F. Margheritini et al. (eds.), Complex Knee Ligament Injuries, https://doi.org/10.1007/978-3-662-58245-9_11

Dr. Philip P. Roessler's name had been missed out in chapter 11. The authors' name has now been updated.

The updated online version of this chapter can be found at https://doi.org/10.1007/978-3-662-58245-9_11

C. I. Murphy · P. P. Roessler · T. J. Lawyer

V. Musahl $(\bowtie)$

Department of Orthopaedic Surgery, University of

Pittsburgh, Pittsburgh, PA, USA

e-mail: murphyci@upmc.edu; musahlv@upmc.edu 